\title{
Cornell misconduct case grinds slowly to its conclusion
}

\section{Washington}

INVESTIGATING scientific misconduct is not easy, a fact underlined by a long, drawn-out investigation of a cardiologist at Cornell University Medical Center in New York that may only now be drawing to a close five and a half years after it was initiated. Cornell has announced disciplinary steps against cardiology researcher Dr Jeffrey S. Borer for scientific practices "below acceptable standards for clinical research". The final chapter in the investigation will come when the National Institutes of Health (NIH) releases a full report on the case.

Cornell's announcement follows the receipt of a final draft of the NIH report. Disciplinary action will include a review of Borer's supervision of research fellows, a review for accuracy of his research papers for a period of at least one year, and a review of a recent published work to make certain that no problems uncovered in the investigation persist.

The doubts about Borer's research stem primarily from a study conducted in late 1981 and ultimately published in the American Journal of Cardiology (Jordan et al. 51, 1091-1097; 1983). The work looked at cold stress as an alternative to strenuous exercise for inducing ischaemia in patients being examined for coronary artery disease. Dr Jerome G. Jacobstein, then co-director with Borer of the laboratory of nuclear cardiology first raised the allegations of misconduct. Jacobstein's concerns were with the way Borer supervised the medical student conducting the research, and with the accuracy of the language in the methods section of initial drafts of the paper. A committee convened by Cornell in December 1981 dismissed Jacobstein's charges, concluding that no further investigation was warranted. Jacobstein left Cornell in March 1982, for Graduate Hospital in Philadelphia where he is director of nuclear medicine.

But Jacobstein was not satisfied that his charges were being given the attention they deserved. Together with his lawyer, George Washington University law school faculty member Harold Green, Jacobstein took his case to NIH.

In January 1983, a team from NIH visited Cornell to investigate the charges against Borer. After receiving a draft of the initial NIH investigation report, Green additionally charged that some of Borer's subjects had been treated with propranolol within 24 hours of participating in the study, whereas the methods section of the paper stated the opposite. In November 1983, NIH informed Cornell of the new charge, and in March 1984, Cornell acknowledged the reporting error.
Borer informed the American Journal of Cardiology of the mistake.

Despite having produced a so-called final report on the case in April 1984, $\mathrm{NIH}$ decided to investigate further. In the summer of 1985 NIH called in two outside experts, Harvey Berger, then director of nuclear medicine at Emory University and Bertram Pitt, director of the cardiology division at the University of Michigan, to review the case. Their review was only transmitted to Cornell in March of this year.

NIH will still not comment officially on the case, since its report is not yet completed. NIH is awaiting comments from Cornell and from Jacobstein and Green before declaring the investigation closed. In a prepared statement responding to the Cornell decision, Jacobstein and Green state they are pleased that "after five and a half years of stonewalling" Cornell is taking Jacobstein's allegations seriously. But the statement goes on to criticize Cornell for characterizing Jacobstein's initial allegations as "disagreements", when they were meant to convey the concern that "Dr Borer had led a medical student to believe that it was not wrong to misrepresent research methodology.

Cornell officials do not feel they are acting prematurely in this case even though NIH has not released a final report. Cornell Dean Thomas Meikle is confident that the NIH investigation has uncovered all the relevant facts in this case. For his part, Borer acknowledges responsibility for an error in a study he supervised, and hopes that the book will shortly be closed permanently on the incident.

Joseph Palca

\section{AIDS campaign}

Australia's television campaign to warn of the dangers of AIDS (acquired immune deficiency syndrome) has been a little too successful. People are flocking for blood tests, with a tenfold rise in attendance at some hospitals. But most of them are not in risk groups, and calls to end the campaign are growing.

The campaign, featuring death in the form of the Grim Reaper, was designed to shock. But it did not inform people of the real nature of AIDS, says Professor David Pennington, chairman of an AIDS education committee, AIDS Task Force. The National Advisory Committee on AIDS, who produced the campaign defend their scare tactics. The committee chairperson, Miss Ita Bullrose (herself "radically celibate") says it has "jolted people out of their apathy".
New rules for AIDS positives

\section{Washington}

US Secretary of Defense Caspar Weinberger last week unveiled new guidelines governing the military's estimated 2,576 personnel who have tested positive for the AIDS (acquired immune deficiency syndrome) virus. So far, 200 out of the $2,100,00$ members of the US combined military forces have contracted AIDS.

Under the new Department of Defense (DOD) AIDS policy, those testing positive for AIDS virus (HIV) will be restricted to duty posts within the United States. According to Dr William Mayer, Assistant Secretary of Defense for Health Affairs, the decision will give infected personnel greater access to primary healthcare facilities, and will make it easier to monitor the onset and progress of symptoms. It is also intended to avoid exposing them to risks associated with immunizations required for foreign duty, and to protect them from diseases endemic to foreign countries that their weakened immune systems might not be able to fend off.

The location and types of assignment of HIV-positive service members may also be limited to "protect the health and safety of military personnel with serologic evidence of HIV infection and of other military personnel". Commanders will have the authority to strip them of security clearances and remove them from posts "requiring a high degree of stability or alertness". No decision has been made on whether infected troops will be sent into battle in the event of mobilization.

Infected reservists and students at military academies or under military scholarships are also affected under the new policy. Members of the reserve corps are no longer eligible for military medical treatment if they contract HIV, and students will be expelled at the end of the term or have their scholarships revoked if they become infected.

The guidelines also include provisions for disciplining members of the military who have the AIDS virus, and who knowingly pass it on. Dr Mayer says those who test positive are counselled on "safe sex" procedures, including the use of condoms. Violating those procedures constitutes breaking a direct order, and can lead to criminal prosecution.

The one million civilians who work for DOD will not be subject to routine testing. However, screening civilians for HIV before sending them overseas on military business is being considered by the Pentagon. The State Department now tests members of the Foreign Service, and has just won a case brought against it that alleged that such routine testing violated workers' privacy.

Carol Ezzell 